\title{
Conflitos em torno do Ministério da Educação: está em curso uma Crise de Hegemonia?
}

\section{Conflicts around the Ministry of Education: is Crisis of Hegemony in progress?}

\author{
Bruno Gawryszewski \\ Universidade Federal do Rio de Janeiro (UFRJ) \\ Joyce Pitz Monteiro \\ Universidade Federal do Rio de Janeiro (UFRJ)
}

\begin{abstract}
Resumo: O presente texto tem como objetivo discutir se está em curso uma crise de hegemonia no Brasil, partindo dos conflitos para montagem da equipe a ocupar os cargos de primeiro, segundo e terceiro escalão no Ministério da Educação nos primeiros quatro meses do governo Bolsonaro. Para tanto, o texto está estruturado em quatro momentos: 1) na introdução, apresentamos o sentido conceitual sobre crise de hegemonia nos termos de Gramsci; 2) reconstituição dos conflitos no Ministério da Educação; 3) exposição e análise da Estratégia Democrático-Popular durante os governos petistas; 4) considerações finais, em que apresentamos a conclusão de que a crise de hegemonia pode ser vislumbrada como uma concreta perspectiva, a depender de fatores como a perda de apoio de demais frações da classe dominante e a irrupção da luta por parte da classe trabalhadora.
\end{abstract}

Palavras-chave: Crise; Hegemonia; Estado; Ministério da Educação.

Abstract: This text aims to discuss whether a crisis of hegemony is underway in Brazil, starting from conflicts to assemble the team to occupy the positions of first, second and third echelons in the Ministry of Education in the first four months of the Bolsonaro government. The text is structured in four moments: 1) in the introduction, we present the conceptual meaning about hegemony crisis in Gramsci's terms; 2) reconstitution of conflicts in the Ministry of Education; 3) exposure and analysis of the Democratic-Popular Strategy during Workers' Party governments; 4) final considerations, in which we present the conclusion that the crisis of hegemony can be seen as a concrete perspective, depending on factors such as the loss of support from fractions of the ruling class and the eruption of the struggle by the working class.

Keywords: Crisis; Hegemony; State; Ministry of Education. 


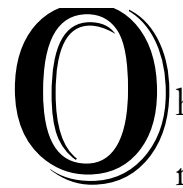

objetivo do presente texto é discutir se está em curso uma crise de hegemonia no Brasil pelo fato de que, embora a burguesia ainda se mantenha como classe dominante, tem passado por entraves em garantir uma estável representação nos postos dirigentes do Estado para seus próprios interesses. Tomaremos como exemplo fenomênico as dificuldades de montagem e manutenção da equipe a ocupar os cargos de primeiro, segundo e terceiro escalões no Ministério da Educação nos primeiros quatro meses de mandato do então recémempossado governo Bolsonaro. Mais especificamente no caso do texto, pretende-se abordar a desestabilização presente entre os gestores estatais alocados no Ministério da Educação que, além de custar o cargo de mais de uma dezena de indivíduos, provocou atritos no âmbito educacional entre o empresariado da educação e o governo Bolsonaro, de uma coalizão que vinha se definhando nos anos finais dos governos petistas.

Por crise de hegemonia, estamos entendendo como a dificuldade que as frações de classe burguesas têm para se impor sobre as classes e frações subalternas a fim de se manter como classe dirigente, o que, em última instância, diz respeito à "crise do Estado em seu conjunto", nos termos de Antonio Gramsci. Ou seja, trata-se de uma crise de descolagem entre as massas populares e as ideologias dominantes, que pode criar "situações imediatas perigosas". Diante disso, a classe dirigente busca se reorganizar rapidamente, se expondo, até, “[...] a um futuro obscuro com promessas demagógicas, mas mantém o poder, reforça-o momentaneamente e dele se serve para esmagar o adversário e desbaratar seus dirigentes" (GRAMSCI, 2000, p. 60-61).

No entanto, é preciso ressaltar que a crise, tal como colocada acima, não se limita aos partidos e sua representação estatal, mas é uma crise que se espraia pelo Estado em seu conjunto, o que inclui a sociedade civil, pois as classes dirigentes, ao manifestar sua incapacidade de dirigir a sociedade, provocam não um vazio de poder, mas, ao contrário, como denominou Bianchi (2002) uma "multiplicidade de poderes" que disputam quem sairá vitorioso para alcançar o controle do poder. Sem perder de vista que, para Gramsci (2007, p. 95) “O exercício 'normal' da hegemonia, no terreno tornado clássico, do regime parlamentar, caracteriza-se pela combinação da força e do consenso, que se equilibram de modo variado, sem que a força suplante em muito o consenso (...)", embora o exercício da hegemonia não navegue por águas calmas, os perigos causados por revoltas e instabilidades torna esse exercício ainda mais tortuoso. 
A crise de hegemonia se expressa de diversas formas, como a própria dificuldade de formar e manter os governos, o que inclui, por suposto, os seus respectivos ministérios. Nesse contexto, em que "cada fração de partido acredita possuir a receita infalível para deter o enfraquecimento do partido como um todo [...] pensa que deve ser o único a formar o governo para salvar o país (...)” (GRAMSCI, 2007, p. 96), a conjuntura abre espaço para que zombeteiros e bufões ponham em prática um personalismo que cria a figura de um arauto de si mesmo que reaparece constantemente na história como imperativo que tem a capacidade para domar a situação de crise.

Considerando que o campo das relações de classes abriga um conjunto diversificado de sujeitos e instituições que, por sua vez, representam variadas frações de classe, torna-se imprescindível a precisa função de organizar e coesionar os múltiplos interesses. Nesse sentido, estamos nos referindo à direção do processo político e, consequentemente, ao exercício da hegemonia no Estado do qual Gramsci denominou que seu sentido integral perpassa pela compreensão de que a hegemonia está couraçada de coerção, ou seja, não obstante com funções diferentes, existe uma unidade orgânica para a conservação e reprodução de uma classe como dominante, tendo em vista a vigência de uma base econômica fundada na propriedade privada e na exploração do trabalho.

A interpretação dos conflitos em torno do exercício da hegemonia requer a compreensão de que o Estado capitalista tem se caracterizado como uma condensação material de uma relação de forças e, por isso, não pode ser entendido como uma unidade harmônica. Ou seja, o Estado como tal não existe meramente como um epicentro de poder e desprovido de atravessamento de relação de forças, pois tal visão denotaria uma incompreensão da natureza do próprio sistema capitalista. Justamente por exercer esse papel de mediador das relações de poder contraditórias e conflitantes, o que inclui por óbvio a contradição entre classes dominantes e dominadas, o Estado capitalista dispõe do que Poulantzas (1986) denomina como "autonomia relativa". Esta assinala a relação do Estado com o campo da luta de classes, no qual, embora o Estado tenha a função de intervir e assegurar a unificação do bloco no poder por uma classe ou fração de classe, a estrutura erigida para sua existência proporciona aos gestores estatais que ocupam tais cargos o poder para mediar esses conflitos e, inclusive, eventualmente, instituir medidas e interesses das classes dominadas. Por isso, pode-se dizer que o exercício da hegemonia procura estabelecer compromissos variáveis e provisórios, desde que não atinjam o fulcro da produção e reprodução capitalista. 
É necessário então indicar que a conjuntura política pode levar a deslocamentos na preponderância de algumas frações de classe em relação a outras. Nesse sentido, partimos do pressuposto de que a eleição de Jair Bolsonaro para a presidência da República friccionou alguns dos acordos com o empresariado no âmbito educacional que já vinham se pavimentando desde o governo Lula. No presente texto, vamos nos restringir à montagem e a manutenção da formação de primeiro, segundo e terceiro escalões no Ministério da Educação nos primeiros quatro meses de mandato presidencial.

Trazendo para a nossa problemática, constatamos que os conflitos no aparelho de Estado têm como um de seus aspectos mais notórios a fragilidade da formação de coalizões governamentais e partidárias. Nessa dificuldade, grassam polêmicas e choques na grande imprensa que, se nem sempre destituem os grupos políticos dos seus postos dirigentes, trazem dificuldades para a agenda das medidas de primeira ordem dos interesses dominantes.

A regressão acentuada do Produto Interno Bruto (PIB) brasileiro em 2015 e 2016 e o pífio crescimento na casa de 1\% entre 2017 e 2019, desde então, tem justificado uma blindagem da imperativa agenda de contrarreforma sobre a renda e direitos dos trabalhadores, que tem sido implementada a passos mais lentos que o desejado por parte das frações burguesas. Por exemplo, a presidência sob Michel Temer foi incapaz de levar adiante a implementação da Reforma da Previdência, pelo desgaste que tal pauta causa junto às classes dominadas, que o apoiava de maneira ínfima, embora tenha conseguido êxitos robustos aos interesses burgueses, como a Reforma Trabalhista e Emenda Constitucional 95.

Com a eleição pelo voto popular, o governo Bolsonaro conseguiu cumprir as demandas das frações de classe dominante em aprovar a Reforma da Previdência e possuía como pauta para 2020 acelerar a privatização de empresas estatais e escoar maior parcela do orçamento público para as frações rentistas, por meio de novas propostas de emenda constitucional. Nessa perspectiva é factível indicar que, mesmo que haja atritos com parcelas de frações burguesas e com as representações parlamentares, nas medidas essenciais o governo Bolsonaro, apesar de sua agenda conservadora-reacionária não estar compatível com a agenda da grande burguesia organizada, tem cumprido um papel ao menos razoavelmente satisfatório ${ }^{1}$.

\footnotetext{
${ }^{1}$ Exemplificamos tal afirmação com a entrevista do presidente da Federação das Indústrias de São Paulo (FIESP) que, em artigo à Folha, escreveu em janeiro de 2020: “Apoiamos o governo Bolsonaro? Sim. Ele promove a agenda econômica que sempre defendemos, de controle de gastos públicos, reformas estruturais, redução de juros, desburocratização... Bolsonaro colocou o país no rumo certo e tem dado
} 
Ciente dos limites do alcance do presente texto, o texto a seguir está organizado da seguinte forma: 1) reconstituição dos conflitos gerados na formação e manutenção da equipe posta para assumir os primeiros escalões do Ministério da Educação nos seus primeiros quatro meses, o que culminou em abril de 2019, na demissão do então ministro; 2) exposição e análise da EDP durante os governos petistas na Presidência da República; 3) considerações finais acerca da interpretação sobre a crise de hegemonia.

\section{Tecendo a precoce trajetória ministerial com Bolsonaro}

Primeiramente, parece-nos razoável afirmar que a educação, a não ser pelos legados dos governos petistas reivindicados pelo então candidato Fernando Haddad (PT), não foi um dos temas centrais da campanha presidencial, tornando-se assunto de segunda ordem aos destaques conferidos à segurança (não necessariamente enquanto política pública); combate à corrupção, que teria "aumentado exponencialmente nos governos petistas, conforme a Operação Lava-Jato mostrou"; déficit fiscal (a tese da gastança, o que impediria um crescimento sustentável a longo prazo); e as estratégias para retomada do crescimento econômico e geração de empregos (como destravar os obstáculos do "custo Brasil').

No que tange à educação, o candidato vencedor do pleito, Jair Bolsonaro, apresentou um programa de governo baseado em afirmações de senso comum e notoriamente montadas no esquema "copia e cola" de documentos e textos recorrentemente veiculados na grande imprensa, sobretudo provenientes de organismos internacionais (aparentemente, pois não há citação de fontes). No documento, está presente a constatação de que há inúmeros problemas educacionais, tais como: dinheiro mal gasto, desempenho insatisfatório nas avaliações de larga escala e evasão escolar, mas não houve a preocupação de apresentar propostas exequíveis sobre como dirimir, a não ser a divulgação de frases de efeito em caixa alta ou letras de coloração vermelha para destacar a polarização de que tudo o que havia de ruim seria herança dos governos petistas. Por fim, o conteúdo do documento acena para a denúncia contra a doutrinação, sexualização precoce e o que denominam como "ideologia de Paulo Freire".

Logo que Jair Bolsonaro terminou vitorioso no pleito presidencial de 2018, as especulações em torno do anúncio do seu ministério alimentaram as diversas bolsas de apostas informais sobre quais figuras estariam ao lado do longevo deputado federal de sete

demonstrações concretas de estar comprometido com o crescimento e com a geração de empregos." (SKAF, 2020). 
mandatos que prometia a instauração de uma "nova política". Para o cargo máximo na educação, o primeiro nome ventilado foi o do brasileiro de origem grega, Stavros Xanthopoylos, desconhecido do grande público, mas um nome que representa os interesses da Associação Brasileira de Educação a Distância, da qual é diretor. Xanthopoylos, na época da campanha, concedeu diversas entrevistas sobre suas ideias de ensino de "moral e cívica do século XXI”, desideologização da educação, ensino domiciliar e pela modalidade à distância.

Embora as ideias do greco-brasileiro aparentemente se sintonizassem com as do presidente eleito, este não despertou maiores entusiasmos entre os intelectuais orgânicos das frações de classe dominantes, particularmente naqueles alinhados às fundações empresariais e recorrentemente ouvidos pela grande imprensa, que preferiam nomes mais "técnicos" e de acordo com a agenda hegemonizada pela organização Todos pela Educaşão (TPE), como Maria Inês Fini e Mozart Neves Ramos.

A primeira, além de ter sido uma professora universitária precursora da Faculdade de Educação da UNICAMP, tem ampla experiência em gestão educacional em diversos cargos no setor público e privado, sobretudo dirigindo o Instituto Nacional de Estudos e Pesquisas Educacionais (INEP) durante o governo Temer (2016-2018). Sem destoar, Mozart possui vastíssimo leque de serviços prestados na universidade pública como Reitor da Universidade Federal de Pernambuco, esteve no comando da Secretaria de Educação do Estado de Pernambuco e no Conselho Nacional de Educação; e constantemente trabalha a serviço das próprias organizações empresariais, como o TPE e pelo Instituto Ayrton Senna (IAS).

Entre os dois, Maria Inês foi publicamente rechaçada em entrevista por Bolsonaro (2018): “Pode esquecer. Essa não esteve à frente do Enem? Está fora, cartão vermelho”. Já Mozart teria sido convidado a assumir o cargo em visita à Brasília em novembro de 2018, quando, acompanhado da presidente do IAS, Viviane Senna, foi entregar a agenda educacional do Todos pela Educação para o quadriênio 2019-2022, intitulada Educaşão Já. No entanto, especula-se que tão logo ocorreu a repercussão negativa junto à sua base parlamentar evangélica, Mozart teria sido desconvidado por Bolsonaro por ser considerado liberal demais, ao não estar alinhado com a pauta autoritária do Escola sem Partido e contra a "ideologia de gênero" e ter seu nome vetado pela bancada evangélica da Câmara, tal como foi expresso pelo deputado Sóstenes Cavalcante (PSD-RJ): "Não dá, ele tem um viés diferenciado do que defendemos. [...] Ele ou outra com viés de esquerda não passarão" (CAVALCANTE, online). Eis que, surpreendendo a todos, em final de novembro, 
Bolsonaro anunciou como Ministro da Educação o colombiano Ricardo Vélez Rodríguez, professor aposentado de Filosofia e Ciências da Religião na Universidade Federal de Juiz de Fora (UFJF) e de instituições privadas no Paraná.

Inicialmente no cargo, Vélez Rodríguez procurou encarnar fielmente a imagem e semelhança de seu chefe imediato. Nos três meses em que durou no cargo, colecionou polêmicas, como o envio de um comunicado para as direções de escolas públicas e privadas para que, no primeiro dia de volta às aulas, os estudantes fossem perfilados para a execução do hino nacional e leitura de uma carta com slogan da campanha eleitoral de Bolsonaro "Brasil acima de tudo, Deus acima de todos" e gravado em vídeo para envio ao MEC, ou ainda, a criação de uma comissão para inspecionar temas da prova do ENEM que façam abordagens "ideológicas" e consideradas controversas a segmentos e grupos sociais, símbolos, tradições e costumes nacionais, o que será desenvolvido no quarto capítulo.

A montagem da estrutura do ministério sob o comando de Vélez Rodríguez trouxe algumas medidas que se alinhavam à plataforma política que elegeu Bolsonaro como presidente. Por exemplo, a extinção da Secretaria de Educação Continuada, Alfabetização, Diversidade e Inclusão (Secadi) se engajou no discurso bolsonarista de combate à "ideologia de gênero" e à representatividade de grupos identitários que se amparariam no discurso "coitadista" para obter "privilégios". Também não é possível ignorar a criação da Subsecretaria de fomento às Escolas Cívico-Militares, justificadas pelo argumento de unir disciplina e bom desempenho nas avaliações de larga escala.

Contudo, apesar do aparente alinhamento de ideias, a acomodação de todos os setores apoiadores de primeira ordem da vitória bolsonarista resultou em uma verdadeira Torre de Babel. Levando em consideração os sujeitos nomeados, é possível afirmar que existiam quatro grupos (que, em alguns casos, tinham interseções com mais de um grupo) que compunham o organograma das indicações para os cargos de primeiro, segundo e terceiro escalões do MEC: 1) militares de carreira ou civis formados em suas instituições, como o Instituto Tecnológico da Aeronáutica (ITA); 2) funcionários públicos de carreira ou técnicos do setor privado com experiência em gestão corporativa; 3) ex-alunos e orientandos do próprio Vélez Rodríguez na UFJF; 4) o inusitado segmento daqueles que foram indicados pelo "polivalente profissional" Olavo de Carvalho (incluindo o próprio ministro), conhecidos como "Olavistas".

Desde o início da nova gestão, a disputa por espaços de poder e o curto-circuito causado por aqueles mais alinhados por supostos pressupostos "técnicos" (tecnocratas neoliberais e militares) e os "conservadores" (olavistas e ex-alunos de Vélez) minou a 
previsibilidade, a segurança e a coesão construída pela hegemonia empresarial no MEC, consolidada tanto nos governos do PT (a despeito de alguma resistência interna de setores ligados à pauta da educação pública) quanto no governo Temer (muito mais coeso para implementação das "reformas educacionais"), o que levou à uma progressiva reação por parte dos intelectuais orgânicos do empresariado na educação e ex-ocupantes de cargos estatais a se manifestarem publicamente utilizando espaço conferido pelos meios de comunicação de massa e no parlamento.

Em 26 de março, o então presidente do INEP, Marcus Vinícius Rodrigues foi exonerado do cargo, um dia depois que a portaria que suspendia a avaliação do nível de alfabetização das crianças brasileiras foi revogada pelo próprio governo. Em entrevista no dia seguinte após sua saída, Rodrigues classificou em entrevista o então ministro como "gerencialmente incompetente" e sem "controle emocional" para ocupar o cargo (RODRIGUES, 2019). No dia seguinte, uma audiência na Câmara dos Deputados foi viralizada por conta da intervenção da deputada paulista Tábata Amaral que o questionou pela falta de diretividade para executar ações concretas no Ministério e por perder tempo com discussões ideológicas, sugerindo-lhe: "Mude de atitude ou saia do cargo!".

O vídeo, além de catapultar a popularidade nacional da deputada, fragilizou de vez a autoridade de Vélez, até que, em 5 de abril, Bolsonaro proferiu a emblemática declaração de que "[Vélez] É uma pessoa honrada, mas está faltando gestão. Na segunda-feira, vamos tirar a aliança da mão direita, ou vai para a esquerda ou vai para a gaveta" (BOLSONARO, 2019). Passados três dias, o presidente optou pela demissão de Vélez Rodríguez. Em levantamento realizado por consulta ao Diário Oficial da União, pudemos constatar que entre a posse do novo governo e a queda de Vélez Rodríguez, ocorreram quase 20 exonerações de nomeados para os cargos dirigentes de primeiro, segundo e terceiro escalões (quantitativo acrescido pela depuração de outros nomes ocorrida posteriormente à nomeação do novo ministro).

Para seu lugar, foi nomeado Abraham Weintraub, professor de microeconomia na Universidade Federal de São Paulo e consultor no mercado financeiro com ênfase em previdência. Weintraub já ocupava um cargo no governo Bolsonaro como SecretárioExecutivo da Casa Civil. Com sua nomeação, quase todos os ex-orientandos de Vélez Rodriguez que ainda restavam foram exonerados de seus cargos e também os Olavistas perderam espaço em favor de nomes com perfil mais "técnico" e que pudessem direcionar a ação do MEC na resolução das questões ainda pendentes da agenda do governo anterior, como a implementação da BNCC, a Reforma do Ensino Médio, a reformulação da 
formação de professores (justamente o que clamavam os colunistas da grande imprensa, o empresariado que tem interesses na educação e os representantes parlamentares, tais como a deputada Tábata Amaral) e as ações que tentam ser a marca do governo na educação, como a tentativa de reestruturação das universidades por meio do programa Future-se, o fomento às escolas cívico-militares, dentre outros.

\section{Remontando brevemente ao passado: a que ponto chegamos?}

\footnotetext{
...o erro foi outro - o de supor que se poderiam atingir esses fins percorrendo a estrada real dos privilégios na companhia dos privilegiados. Não há reforma que concilie uma minoria prepotente a uma maioria desvalida.

Florestan Fernandes, 1977.
}

Para compreender o movimento do real no presente, realizaremos o esforço de uma síntese, dentro dos limites e objetivos deste texto, de alguns dos determinantes da história recente para os fatos ocorridos no atual governo, descritos na sessão anterior deste capítulo.

Acreditamos que um dos fatores essenciais a serem trazidos para esta breve análise seja a estratégia hegemônica da esquerda brasileira, encarnada pelo Partido dos Trabalhadores como polo aglutinador da classe trabalhadora organizada por meio de sindicatos e movimentos sociais e que foi posta em curso desde o período de redemocratização pós-ditadura empresarial-militar. Tal estratégia política se valia da combinação de dois movimentos concomitantes: a construção de um movimento de caráter socialista na sociedade civil em pretenso compasso de ritmo com o movimento de conquista de espaços institucionais na sociedade política, o que alegoricamente ficou conhecido como movimento de pinça.

A pretensão declarada é que gerasse as condições necessárias para que chegássemos, um dia, ao socialismo, através do aprofundamento da democracia e de conquistas sociais (IASI; FIGUEIREDO; NEVES, 2019, p. 15), o que se acreditava que contribuiria para o avanço da consciência de classe dos trabalhadores como um todo. Este processo seria possível através de um governo de coalizão dirigido por um partido da classe trabalhadora (no caso, o PT). Deixava-se, desta forma, o objetivo socialista de lado, momentânea ou permanentemente, por compreender que este movimento seria necessário para o amadurecimento das condições objetivas e subjetivas para a transição ao socialismo.

Faz-se necessário registrar que o objetivo da análise crítica da EDP aqui realizada não se volta apenas para um partido político - embora o PT tenha sido seu principal 
representante -, pois representa o pensamento hegemônico da esquerda há mais de 30 anos, derivado das análises de conjuntura e estratégias traçadas pelos principais teóricos da época, de acordo com os determinantes objetivos e processos históricos em que estavam envolvidos. De nada adiantaria ficarmos aqui procurando apontar "culpados" pelos erros passados. Não se trata, também, do embate de perspectivas de determinado partido/grupo político contra outro. Buscamos, através da compreensão dos erros passados, contribuir para compreensão dos processos nos quais estamos imersos na atual conjuntura, para que assim possamos, enquanto esquerda, elaborar novas possibilidades estratégias de ação da classe trabalhadora (inclusive, no sentido do avanço da consciência de classe por parte dos trabalhadores, para que possa existir de fato como sujeito e organizar-se coletivamente).

O governo de Fernando Henrique Cardoso, em seus dois mandatos como presidente (1995-1998 e 1999-2002) representou até então o auge brasileiro de implementação de políticas neoliberais (embora com modulações no campo social, a fim de obter algum apoio da classe trabalhadora e camadas médias), com reformas estruturais orientadas para o mercado (como as privatizações, a liberalização comercial e a abertura externa), rompendo com aspectos políticos e econômicos do modelo anterior, sobretudo em relação à estratégia de desenvolvimento e da estrutura produtiva do país. A economia foi rearranjada tornando-se mais dependente de produtos direta ou indiretamente extraídos da natureza - as commodities - para fortalecer as exportações. Este processo, junto às privatizações e ao aumento da entrada de capital estrangeiro, causou uma mudança no perfil econômico do país, provocando uma reestruturação produtiva onde parte expressiva do empresariado nacional foi atingida. Para Diniz (2005, p. 25), nesse momento

[...] delinearam-se duas correntes: a visão desenvolvimentista, reivindicando uma maior participação do Estado no estímulo aos setores produtivos e na regulamentação e fiscalização da concorrência com o capital estrangeiro, e uma política industrial capaz de fortalecer as empresas nacionais e garantir a retomada do crescimento; e, em contrapartida, os defensores de uma postura mais restritiva. Tais defensores viam na retomada do desenvolvimentismo uma potencial ameaça à estabilidade. Para essa corrente, seria mais adequado manter a austeridade fiscal, a continuidade das privatizações o estímulo ao ingresso de capitais estrangeiros, o aprofundamento da internacionalização da economia, o livre mercado e a redução do papel do Estado na economia.

Lideranças do PT, ao compreenderem este cenário, passaram a defender a necessidade de o partido formular uma nova estratégia, mais ao centro, moderando suas posições políticas, com um discurso moderado, a valorização da política no contexto democrático e a relevância da negociação e da tática de alianças para chegar ao poder (MARTINS, E. 2013, p. 20). 
Alguns dos marcos que evidenciaram o pacto capital-trabalho, meta do governo Lula, foram: a coalisão com o Partido Liberal, com o empresário José de Alencar como vice-presidente da chapa (assim como, após a eleição, indicação de outros empresários para integrar a equipe ministerial e outros órgãos do governo); a Carta ao Povo Brasileiro (LULA DA SILVA, 2002), onde defendeu o respeito aos contratos e compromissos internacionais e se comprometeu com outras pautas do empresariado, como o crescimento com estabilidade econômica e responsabilidade fiscal; a Nota sobre o acordo com o FMI, reafirmando o compromisso de respeitar o acordo com o FMI negociado no final do governo de Fernando Henrique.

Esse novo discurso contribuiu de modo significativo para que alguns partidos de centro-direita passassem a ver o partido dos trabalhadores como um interlocutor mais confiável e manifestassem abertamente seu apoio à chapa. Ainda antes do primeiro turno das eleições de 2002, setores da Fiesp, da Bovespa e da Febraban, além de um grupo composto por mais de 100 empresários, assinaram um "Manifesto de apoio a Lula".

Dessa forma, durante o período dos governos petistas, foi materializado um governo de coalizão entre diversos setores, onde o núcleo duro da economia ficou a cargo das frações de classe dominantes do bloco no poder, denotando assimetrias na coalisão, de forma que o governo mediou diversas pautas dos trabalhadores para que conseguisse garantir a governabilidade. Tal processo ocorreu não só no âmbito institucional, do aparelho estatal stricto sensu, mas também, e sobretudo, por meio do aparelhamento institucional das entidades (sindicais e estudantis) e movimentos sociais que eram dirigidos pelo PT.

Haviam concluído, a partir de um suposto realismo político, que seria necessário não apenas adiar qualquer maior ambição de igualdade social, mas também operar a capitalização das políticas de direito social que tornassem possível a permanência no governo, implementando a "política do possível”. Desse modo, construía-se um malfadado reformismo que vislumbrava a humanização do capital escamoteado como mais democrático, negligenciando assim problemas cruciais relacionados a processos de ruptura com a ordem burguesa, como destacam Iasi, Figueiredo e Neves (2019, p.16):

Buscam-se formas de pacto em que seja possível mitigar seus aspectos considerados socialmente mais deletérios, mantendo-se as relações sociais em sua base. Respeitam-se o sociometabolismo do capital, as relações de propriedade privada, a possibilidade de compra e venda de força de trabalho, mas pretende-se alcançar a equidade, ou inclusão da massa historicamente deserdada, através da ampliação de direitos, ou, na versão rebaixada, da consolidação de um pujante mercado interno e da universalização do acesso a ele. Tudo isso se articularia a medidas distributivas operadas através do aparelho estatal. Para alguns, essa 
equidade seria o primeiro passo para consolidar as condições para o advento progressivo, num futuro indeterminado, do socialismo. Para outros, seria o próprio objetivo da luta política após a falência das experiências do Leste, que teria demonstrado a inviabilidade histórica definitiva do sonho socialista. Na prática, a igualdade social passa a ser tratada, na melhor das hipóteses, como ideia reguladora, posta em um horizonte ao qual se pode, quem sabe um dia, chegar.

O que ocorreu na prática foi que as próprias concessões realizadas pela burguesia na arena das disputas de interesse por dentro do Estado foram funcionais ao capital, seja no sentido do apassivamento da classe trabalhadora, seja na própria geração de valor, através das diversas formas de privatização da prestação de serviços públicos. Ou seja, as concessões dadas aos trabalhadores em troca da coalizão que garantiu a governabilidade foram limitadas a políticas sociais nos moldes neoliberais (programas assistencialistas minimalistas e focalizados, na perspectiva do filantropismo) ou ampliação do crédito popular, que contribuíram elas mesmas para o apassivamento dos trabalhadores, que obtiveram sucessivos aumentos reais na base do salário mínimo durante os governos petistas.

No capitalismo uma das principais funções do Estado é o apassivamento da classe trabalhadora, agindo para a manutenção da reprodução da base material existente, em função dos interesses burgueses. Nesse sentido, o PT foi funcional (e fundamental) à burguesia, pois conseguiu cumprir tal papel durante treze anos de governo, devido à sua ampla base de apoio, até os impactos da crise orgânica do capital chegarem ao Brasil, impossibilitando a continuidade da política conciliadora que vinha sendo implementada até então.

A estratégia de promoção da corresponsabilidade entre o aparelho de Estado e sociedade civil foi mantida como parte da ideologia difundida pelos organismos internacionais (OI), só que aprofundada pela maior capilaridade que o PT dispunha em bases no polo da luta de classes por parte dos trabalhadores. Nesse sentido, o aparelho de Estado exerceu seu papel de manter a estabilidade, adotando medidas de ajuste e controle fiscal e garantindo os investimentos públicos, assim como ações para a promoção da inclusão social e à sociedade civil foi reservado espaço de protagonismo para cimentar o pacto de classes, outrora antagônicas, em prol da prosperidade da nação.

Capital e trabalho, empresários e trabalhadores, podem e devem construir juntos os alicerces do desenvolvimento. As condições políticas, sociais e econômicas para a superação da crise estão a um passo. Cabe a cada um, Governo e sociedade, fazer a sua parte (BRASIL, 2004, p. 18). 
Trata-se do que Francisco de Oliveira denominou como um caso de "hegemonia às avessas", porque os setores historicamente subalternizados e dominados que ascenderam ao poder do Estado e aparentemente conferem a direção moral da sociedade, implementam com retidão a agenda que atende, prioritariamente, as frações burguesas locais e o capital internacional. Segundo seu entendimento,

Não são mais os dominados que consentem em sua própria exploração; são os dominantes - os capitalistas e o capital, explicite-se - que consentem em ser politicamente conduzidos pelos dominados, com a condição de que a "direção moral" não questione a forma da exploração capitalista (OLIVEIRA, 2010, p. 27)

Com isso, o governo federal pôde angariar apoio suficiente para se blindar diante de quaisquer crises que viessem a ocorrer, como no caso de corrupção conhecido como "mensalão" e, de modo mais profundo, no contexto da crise que se agudizou em 2008, notadamente a partir dos EUA, exigindo enorme deslocamento de recursos para os bancos e para diversos setores econômicos, desacelerando os gastos sociais e, posteriormente, causando importantes cortes nos gastos sociais, tudo isso sem contestação social relevante. O apaziguamento e consentimento dos setores subalternos da sociedade muito favoreceram o bloco de poder operado pelo governo Lula

Nesse sentido, foi criado um canal institucional de consulta, o Conselho de Desenvolvimento Econômico e Social (CDES), que serviria como instrumento de geração de consenso e estabelecimento de diretrizes para o desenvolvimento. Contudo, embora a justificativa da criação do CDES seja permeada de valores com espírito democrático-liberal, de abertura para maior participação da sociedade, sua composição evidencia que fez parte das estratégias utilizadas pelos governos Lula para abertura de canais de participação empresarial nas instâncias de articulação política e econômica na aparelhagem do Estado (GUIOT, 2012 apud MARTINS, E. 2013, p. 25).

Faz-se necessário, também, compreender a relação dos OIs com o que se passava nesse momento no Brasil. A situação econômica brasileira no século XXI faz com que o país passe a incluir novas prioridades em sua agenda, onde se incluem as reformas no sistema educacional. Para Freitas (2011, p. 4-5 apud MARTINS, E. 2013, p. 26):

Economicamente, o Brasil é hoje muito diferente do que à época das primeiras tentativas liberais de implantar esta política educacional. Hoje é um candidato a país emergente com alto grau de investimentos produtivos e que, portanto, chama a atenção do capital internacional como palco de alocação de recursos. Isso faz com que as corporações se organizem para garantir as condições gerais de funcionamento adequadas à realização do lucro sobre os investimentos, envolvendo redução da 
miséria (e consequentemente das turbulências que ela causa, as quais afugentam o capital); o desenvolvimento da infraestrutura (o PAC) e, é claro, a melhoria da qualidade da educação, entendida esta como um subsistema da produção - entre outros aspectos. Estes fatores exercem fortes pressões de curto prazo, em especial no campo da política educacional.

Para o Banco Mundial (BM), a ascensão dos países de renda média intensifica a necessidade do aumento da competitividade mediante o desenvolvimento de força de trabalho mais capacitada (BANCO MUNDIAL, 2011, s/p). Diante dos "desafios do século XXI", que envolvem os avanços tecnológicos e os altos níveis de desemprego entre os jovens, sobretudo por conta da crise orgânica, o BM lança a publicação Estratégia 2020, com o objetivo de alcançar a "educação para todos". Tais reformas incluem "regras, políticas e mecanismos de responsabilização que aglutinam um sistema de educação [...] A abordagem da nova estratégia ao sistema educacional centra-se em maior responsabilização e resultados [...]" (BANCO MUNDIAL, 2011, p.5).

Os OIs, em sua histórica influência nas políticas públicas de educação dos países subalternizados no capitalismo, mantêm-se ativos na formulação de novas agendas para políticas educacionais e em outras áreas estruturais, sobretudo na econômica. É possível observar que vêm atuando como intelectuais orgânicos coletivos, pois: "mobilizam setores, promovem parcerias, exercem influência e pressões sobre os governos no sentido de reformar as políticas educacionais, incorporando outros sujeitos nos processos decisórios, sobretudo os setores empresariais.” (MARTINS, E. 2013, p. 28).

Tal processo, obviamente, não ocorre de forma totalmente vertical, sem a mediação de frações que compõem a burguesia local. Os OIs encontram aliados, incorporando interlocutores dentre os intelectuais que atuam junto às instâncias de poder, nas universidades, nas mídias, nos partidos políticos, nos movimentos sociais e em outras organizações da sociedade civil. Este é o caso de alguns dos sócio-fundadores do TPE ligados a OIs como Banco Mundial, Banco Interamericano de Desenvolvimento (BID), Unesco (Organização das Nações Unidades para Educação, Ciência e Cultura), entre outros.

Tal fração da burguesia brasileira inclui-se no que Neves (2010) denomina como “direita para o social", que expressa o movimento do capital de manter a coesão social por meio de um equilíbrio entre forças frente à crise orgânica. Pela especificidade políticoideológica, essa fração vem se colocando como setor importante na mediação e condução de mecanismos que venham a amenizar expressões da "questão social", com a promessa de realização do chamado capitalismo de face humanizada. Opera suas estratégias de obtenção 
de consenso por meio de seus Aparelhos "Privados" de Hegemonia, onde difundem seus preceitos ideológicos de base moral, intelectual, social, econômica e política. Assim, busca o consentimento ativo de seus aliados a fim de obter força política e o consenso espontâneo das massas para que se acredite que a vida só é possível nos limites da sociabilidade e do modo de produção capitalista, além de naturalizar as "condições estruturais mínimas e a forma residual do modo de ser burguês" (FERNANDES, F. 1981, p.69) que constitui a formação social brasileira.

Sobre a formação social brasileira, Fontes (2010) aponta que o Brasil se insere de forma subordinada no sistema do capital-imperialismo mundial, fazendo com que aqui a exploração se materialize em superexploração, aumentando os níveis de concentração de renda e polarização social, de forma que a desigualdade e a miséria atingem níveis mais dramáticos. Tal condição exige que se inovem e intensifiquem as formas de obtenção do consenso constantemente, por conta das condições pouco favoráveis. A "direita para o social" reconhece que os efeitos deste processo de intensificação da exploração são um risco para a legitimidade do sistema e para o empresariado como dirigente deste processo histórico.

Essa fração da burguesia passou então a construir novas estratégias para a disseminação de valores, crenças e comportamentos compatíveis com o projeto hegemônico, difundindo a ideia de que as mudanças na política e no "mundo do trabalho" teriam gerado o surgimento de um "terceiro setor", localizado entre o Estado e o mercado, onde predominaria o espírito da iniciativa privada com sentimento público, comprometido com a busca de soluções para os problemas sociais que o Estado não seria capaz de resolver (MARTINS, A. 2015, p. 74).

Segundo André Martins (2015, p. 72), a novidade da "direita para o social" está em sua capacidade de inovar sem perder os vínculos orgânicos com sua classe, afirmando, na educação política, a importância da participação social e da renovação da cidadania; e na educação escolar, defendendo a educação pública e de qualidade para todos. Em ambos os casos os enunciados parecem convergir com as pautas defendidas historicamente pelos setores progressistas. Logo, a bandeira da qualidade da educação para todos, que havia figurado até então somente nas mãos da esquerda, parecia ter mudado de lado. A disputa pelo conceito de "qualidade" - nítida nos debates acerca da construção das políticas que determinam diretrizes e parâmetros educacionais e, sobretudo, no que tange às avaliações centralizadas de larga escala - revela uma tensão político-ideológica, envolvendo os interesses das diferentes classes e frações de classes em disputa. 
E é com estes grupos empresariais (ou representantes de seus interesses), nacionais e internacionais, neste contexto histórico suscintamente resumido, no panorama geral que aqui trazemos, com algumas de suas determinações históricas, que o Partido dos Trabalhadores materializou seu governo de coalizão, com base numa pretensa estratégia gradualista de contínuo e progressivo acúmulo de forças por dentro do aparelho estatal, que acreditamos ter demonstrado que não tinha qualquer base material, nem organização política de objetivos contra a ordem.

Contudo, como demonstra Iasi (2019, p. 433) tal estratégia, que não foi exclusiva do PT, foi formulada a partir de alguns equívocos, dentre eles: sobre a natureza da formação social brasileira no atual estágio de desenvolvimento da ordem capitalista mundial e sobre as implicações disto para a dinâmica da luta de classes, para o caráter de classe e sua morfologia (que envolve o desenvolvimento da consciência enquanto classe, para constituir-se em sujeito histórico) e para a forma política do Estado brasileiro. O autor enfatiza a centralidade deste último ponto:

O terceiro eixo nos parece fundamental, até porque implica nas duas dimensões primeiramente anunciadas. Uma incompreensão do caráter do Estado no Brasil, a crença no amadurecimento de uma suposta sociedade civil que poderia se tornar o terreno para o amadurecimento de formas democráticas que interessam fundamentalmente aos trabalhadores, criando a ilusão segundo a qual o terreno em que se desenvolveria a luta de classes seria o do Estado Democrático de Direito, no qual as formas mais claramente violentas e repressivas seriam anacronismos a serem superados pelo aperfeiçoamento institucional e jurídico e pelo peso, cada vez maior, do protagonismo das massas populares no cenário político. (IASI, 2019, p.433)

Como podemos perceber, foi uma estratégia formulada a partir de algumas "verdades consagradas", nos termos de Caio Prado Jr., pressupondo a possibilidade de um desenvolvimento capitalista que permanecesse tendo algum potencial civilizatório e de amenização das desigualdades sociais, que atendesse minimamente às condições para uma vida digna da população como um todo. O que pressupõe, por sua vez, um protagonismo político dos trabalhadores enquanto classe - como sujeito histórico que se compreenda como tal e, portanto, passível de ação consciente e com objetivo definido - para que se realizasse a pressão necessária por suas reinvindicações e, também, uma forma democrática onde tais tensionamentos se convertessem em políticas públicas, a partir de uma correlação de forças favorável que fosse suficiente para neutralizar o caráter de classe do Estado (IASI, 2019).

A condição para tal é a tentativa de conciliação de classes e a necessidade da existência de uma pré-condição econômica favorável que viabilize essa conciliação de 
interesses, que como sabemos, são opostos. Ou seja, contraditoriamente, faz-se necessário um desenvolvimento capitalista capaz de manter as taxas de lucro em constante ascensão para que sobre algum recurso financeiro para ser investido em políticas sociais voltadas para a diminuição das desigualdades. Dessa forma,

O terreno material se desfaz sob os pés desta intencionalidade política, fundamentalmente por três fatores ligados aos eixos de nossa análise crítica. Não há espaço para um desenvolvimento capitalista sustentável na perspectiva esperada, e isso se dá não apenas pelo caráter dependente e subordinado ao imperialismo (pois isso poderia supor uma forma menos subordinada e dependente), mas pela natureza mesma da forma capitalista plenamente desenvolvida e associada ao capital imperialista. [...] Essa forma capitalista plenamente desenvolvida implica em novas formas de ser das classes e, em especial, do proletariado, que, no entanto, não alteram no substancial, pelo contrário aprofundam, a necessidade de exploração do trabalho e a forma privada, cada vez mais centralizada e concentrada monopolisticamente, da acumulação da riqueza socialmente produzida. Altera-se a subjetividade da classe, em nossos termos sua consciência de classe, impondo-se a fragmentação e a invisibilidade da classe trabalhadora intensificando-se as formas de exploração e opressão sobre o conjunto dos trabalhadores e das camadas expropriadas. (IASI, 2019, p. 434)

Assim, analisando as bases que estruturaram a construção da Estratégia Democrático-Popular do PT, concluímos que em um momento de crise ela não se sustentaria. A crise estrutural do capital, em processo sobressalente desde a década de 1970 e que alcançou um pico em 2008, atingiu primeiramente os países centrais do capitalismo (de maneira geral, Estados Unidos e Europa), demorando um pouco mais para que suas consequências fossem sentidas no Brasil e outros países periféricos. Porém, quando a crise para nós deixou de ser uma simples "marolinha", nas palavras do ex-presidente Lula, e seus impactos na economia passaram a ser sentidos pelo empresariado, tornou-se latente não apenas a necessidade do capital de acelerar o ritmo com que estavam sendo tocadas as reformas, mas também de ampliá-las. Tornou-se inviável para o PT tocar sua política conciliatória, pois os impactos da crise fizeram minar rapidamente a base material que a viabilizava.

Tais fatores, somados a um ambiente de profunda instabilidade política e ascensão de movimentos populares por todo o mundo (como no caso da Primavera Árabe), aqui culminaram nas manifestações que ficaram conhecidas como Jornadas de Junho, em 2013. Tal movimento, que levou milhões às ruas de todo o país e nasceu de forma espontânea, tendo como estopim um aumento no valor das passagens, foi uma janela de possibilidades que se abriu e que a princípio não tínhamos certeza de que rumo tomaria. 
Aquele momento de acirramento das contradições entre os interesses das classes em luta foi sem dúvida uma importante oportunidade histórica de radicalização dos trabalhadores por seus direitos. No entanto, após 13 anos de um governo supostamente de esquerda e popular realizando uma política conciliatória que desmobilizou suas bases, tínhamos uma classe trabalhadora descrente na continuidade do mesmo.

Esse contexto foi um prato cheio para a direita conservadora-reacionária, que sempre foi bastante presente na cultura brasileira e já vinha há alguns anos crescendo e ampliando sua atuação por dentro do aparelho estatal (compondo, no congresso, a famosa "bancada BBB": bíblia, bala e boi) e na sociedade como um todo, sobretudo através de instituições como as Igrejas e as Forças Armadas. Os trabalhadores, em sua maioria desorganizados politicamente após tantos anos de conciliação e apassivamento, e como parte de uma classe fragmentada que é constantemente bombardeada com as bases ideológicas do capital, aderiu, em parte, ao discurso dessa direita conservadora-reacionária que se apresentava como o "novo" na política - um novo curiosamente composto por bancadas que já atuavam na política há décadas, ou melhor, desde que existe o Estado brasileiro.

Foi nesse cenário extremamente polarizado que aconteceu a eleição presidencial de 2014. Dilma ficou à frente de Aécio Neves (PSDB) no segundo turno com uma diferença percentual reduzida (51,64\% contra 48,36\% dos votos válidos), o que abriu brecha para discursos de que teria ocorrido fraude e para os subsequentes pedidos de impeachment que culminaram no Golpe Parlamentar-Judicial de 2016. Assumiu então a presidência o vice Michel Temer, do PMDB, possibilitando a aceleração do ciclo de reformas demandado pelos setores dominantes no contexto de agravamento da crise, realizando a contrarreforma trabalhista, a Emenda Constitucional $n^{\circ} 95$ (do teto de gastos, que congela os investimentos em educação e saúde por 20 anos) e gestando a da previdência. No campo educacional, deu continuidade à agenda dos reformadores empresariais, já presente no período petista, implementando a Base Nacional Comum Curricular e o Novo Ensino Médio, porém em bases autoritárias. Tudo em um período de pouco mais de dois anos de governo.

Temer serviu como solução provisória, um "tapa buraco" para entregar algumas contrarreformas, mas não possuía estabilidade política nem uma base que o permitisse dirigir politicamente o processo após o fim do mandato. Por sua vez, as frações dominantes da burguesia por si mesmas não conseguiram dar uma solução para a crise econômica desde 2014. Alguns setores à direita entendiam que a ascensão de Bolsonaro seria essa 
saída, gerando um padrão de dominação com traços de fascistização, apoiada nas Forças Armadas sob a égide da moral e base econômica neoliberal puro-sangue da Escola de Chicago, com Paulo Guedes como legítimo representante à frente da equipe econômica. Contudo, a priori, esse posicionamento não era consenso entre as diferentes frações da burguesia, de forma que chegam às eleições de 2018 com candidaturas fragmentadas, sem um projeto bem definido e sem uma candidatura com força suficiente para encarnar o sentimento antipetista. Mas, por fim, a aposta das frações mais reacionárias da burguesia na figura do "mito" com discurso populista fincado em jargões do senso comum é a que acaba ganhando o apoio popular, a partir de uma campanha alavancada pelas redes sociais.

\section{Caminhamos para uma crise de hegemonia? Considerações finais}

Decerto que responder a essa pergunta em pleno processo de crise econômica e política e, mais recentemente, sanitária (por conta do coronavírus), não é uma tarefa simples. No entanto, podemos apontar que, a julgar como marco histórico o ano de 2013, ano de irrupção dos protestos simultâneos em nível nacional, trata-se do oitavo ano consecutivo sem que haja uma condição de exercício da hegemonia sem qualquer verniz de pacificação social (embora é preciso que se diga que a pacificação e mesmo a idealização de democracia consolidada nunca ocorreu de fato, vide os conflitos constantes no campo e o extermínio da classe trabalhadora residente nas favelas e periferias urbanas).

Muito tem se discutido sobre a incapacidade dos partidos e de figuras públicas em funcionar como porta-vozes dos anseios de determinado grupo ou classe social. É fato que desde junho de 2013 a guinada de soluções políticas à direita tem sido proeminente; mas também a aparente indestrutibilidade de Bolsonaro, em plena ascensão à Presidência da República em janeiro de 2019, não parece mais estar se concretizar. Por isso, o governo comandado pelo capitão da reserva tem realizados sucessivos rearranjos, especialmente acomodando cada vez mais militares de carreira em cargos-chave, de modo a garantir uma base de apoio por uma instituição de Estado fundada na hierarquia e obediência e que tem ramos que se espraiam nas polícias estaduais e milícias locais.

Não obstante, quando falamos da crise de hegemonia de uma dada nação, não podemos, de nossa parte, ignorar que também pode estar associada materialmente à crise de acumulação e reprodução do capital. Por conta das próprias contradições que lhe são inerentes (tais como a tendência à queda da taxa de lucro, dentre outras), as crises de hegemonia podem reverberar em crises orgânicas, constituídas por fraturas entre a 
estrutura e superestrutura "[...] que nascem no momento em que a superestrutura se desenvolve em não conformidade com a estrutura” (LA PORTA, 2017, p. 163).

A exemplo do que foi exposto sobre os primeiros quatro meses do Ministério da Educação no governo Bolsonaro, podemos entender que as dificuldades apresentadas para a formação e manutenção dos quadros do ministério, está envolta de uma situação de crise econômica, na qual abre-se brechas em potencial para alavancar uma disputa entre as frações parlamentares, o que resulta não apenas na dificuldade dos governos em formar suas equipes, como para se manterem de pé, tendo em vista o tensionamento causado pela própria luta de classes. Tais conflitos no interior do Estado Integral fragilizam os acordos previamente estabelecidos que geravam o consentimento das forças políticas. Nesse sentido, a formulação de Gramsci nos parece emblemática para ilustrar que

Em um certo ponto de sua vida histórica, os grupos sociais se separam de seus partidos tradicionais, isto é, os partidos tradicionais naquela dada forma organizativa, com aqueles determinados homens que os constituem, representam e dirigem, não são mais reconhecidos como sua expressão por sua classe ou fração de classe. Quando se verificam estas crises, a situação imediata torna-se delicada e perigosa, pois abre-se o campo às soluções de força, à atividade de potências ocultas representadas pelos homens providenciais ou carismáticos. (GRAMSCI, 2007, p. 60)

Por isso, frisamos que, embora Jair Bolsonaro não fosse o candidato preferencial das frações de classe dominante, a insuficiente pujança das candidaturas de seus representantes puro-sangue, como Alckmin e Meirelles, levou a que essas frações burguesas optassem por aquela candidatura que pudesse lograr a agenda de contrarreformas no ritmo desejado, de modo a impedir qualquer tipo de tensionamento, sobretudo pela ainda não cicatrizada deposição de Dilma Rousseff e a prisão do ex-presidente Lula.

Não queremos atribuir um nexo causal de que necessariamente uma situação de crise, tal como ocorreu na conjuntura em que Gramsci viveu e resultou na ascensão do fascismo, também tenha levado a ascensão de um conservadorismo autoritário na figura do presidente eleito. Queremos trazer à tona o fato de que o Brasil tem uma conjuntura complexa, mas que se caracteriza pelo abalo da coalizão costurada pelos governos do PT enquanto estiveram na direção do Estado brasileiro e, em meio aos processos analisados, culminaram na eleição de um presidente que não era, a princípio, desejado pela classe dominante. No entanto, se ainda nos parece cedo para afirmar tanto que Bolsonaro tenha se constituído como uma nova hegemonia ou como que esteja instaurada uma crise de hegemonia, apresentamos que essa condição como uma possibilidade razoável de ocorrer. 
Uma crise de hegemonia pode ser resultante de um interregno, que abrange a dificuldade de o velho morrer e do novo em nascer em um regime político. Só que nesse interregno, como Gramsci se refere, o novo a nascer pode expressar sintomas mórbidos, tal qual o que se apresenta como o novo no Brasil. Ao passo que os arranjos políticos que conduziram recentemente o Brasil estão em crise, a morte das velhas ideologias e figuras emblemáticas abre espaço para ceticismos na sociedade, que podem resultar em novas práxis políticas. O tempo presente está permeado pelas chamadas pós-verdades, em que a política é conduzida com base em ficções por quem detém o poder de construir e disseminar determinadas narrativas que são validadas pelo senso comum (FERNANDES, S. 2019).

Até o presente momento, as forças políticas que representam o autoritarismo, a reação e, não menos importante, o capitalismo, têm sido vitoriosas em seu intento de dar respostas à crise instaurada. Essa derrota, embora não seja definitiva, implica na necessidade de um esforço da esquerda para conseguir interpelar a classe trabalhadora a construir e renovar um projeto estratégico. E é esse o elemento fundamental que ainda resta para alavancar a luta de classes. 


\section{Referências}

BANCO MUNDIAL. Estratégia 2020 para a Educação do Grupo Banco Mundial. Resumo Executivo. Washington, Banco Internacional para a Reconstrução e Desenvolvimento. Banco Mundial, 2011. Disponível em: $<$ http://siteresources.worldbank.org/EDUCATION/Resources/ESSU/4632921306181142935/Portguese_Exec_Summary_ESS2020_FINAL.pdf>. Acesso em: 11/2019.

BIANCHI, A. Crise, política e economia no pensamento gramsciano. Novos Rumos, Marília, ano 17, n. 36, p. 28-37, 2002.

BOLSONARO, J. Bolsonaro descarta Maria Inês Fini, presidente do Inep, como ministra da Educação. [Reportagem escrita por] Fábio Grellet. UOL, Notícias, publicado em: 19 nov. 2018. Disponível em: https://noticias.uol.com.br/ultimas-noticias/agenciaestado/2018/11/19/bolsonaro-descarta-maria-ines-fini-presidente-do-inep-como-ministrada-educacao.htm. Acesso em: 12 out. 2019.

BOLSONARO, J. 'Aliança pode sair da mão de Vélez e ir para a gaveta', diz Bolsonaro sobre possível demissão de ministro. [Reportagem escrita por] Allan Gripp e Paulo Celso Pereira. O Globo, publicado em: 5 abr. 2019. Disponível em: https://oglobo.globo.com/brasil/alianca-pode-sair-da-mao-de-velez-ir-para-gaveta-dizbolsonaro-sobre-possivel-demissao-de-ministro-23575382. Acesso em: 12 out. 2019.

BRASIL. Presidência da República. Democracia Participativa. Nova relação do Estado com a Sociedade: 2003 - 2010. 2. ed. Brasília, Secretaria Geral da Presidência da República, 2011c.

CAVALCANTE, S. Bancada evangélica promete barrar nomes de esquerda no governo Bolsonaro. [Reportagem escrita por] Catarina Alencastro. O Globo, Brasil, publicado em: 22 nov. 2018. Disponível em: https://oglobo.globo.com/brasil/bancada-evangelicapromete-barrar-nomes-de-esquerda-no-governo-bolsonaro-23252063. Acesso em: 4 dez. 2019.

DINIZ, E. Empresário, Estado e Democracia: continuidade e mudança entre os governos Fernando Henrique e Lula. In: ¿La esperanza venció el miedo? Una evaluación de los primeros años del gobierno Lula en Brasil. Universidad de Salamanca, 2005.

FERNANDES, F. Sociedade de Classes e subdesenvolvimento. $4^{\mathrm{a}} \mathrm{ed}$. Rio de Janeiro/RJ: Zahar, 1981.

FERNANDES, S. Sintomas mórbidos: a encruzilhada da esquerda brasileira. São Paulo: Autonomia Literária, 2019.

FONTES, V. O Brasil e o capital-imperialismo: teoria e história. 2 ed. Rio de Janeiro: EPSJV/Editora UFRJ, 2010.

FREITAS, L. C. Responsabilização, meritocracia e privatização: conseguiremos escapar ao neotecnicismo? In: III Seminário de Educação Brasileira. Simpósio PNE - Diretrizes para Avaliação e Regulação da Educação Nacional. Campinas: CEDES, 2011. 
GRAMSCI, A. Cadernos do Cárcere. Volume 3.3 ed. Rio de Janeiro: Civilização Brasileira, 2007.

IASI, M. L; FIGUEIREDO, I. M; NEVES, V (orgs.). A estratégia democráticopopular: um inventário crítico. Marília: Editora Lutas Anticapital, 2019.

IASI, M. L. Epílogo: O inventário da estratégia democrático popular e a busca de um caminho para a revolução brasileira. In: IASI, M. L; FIGUEIREDO, I. M; NEVES, V (orgs.). A estratégia democrático-popular: um inventário crítico. Marília: Editora Lutas Anticapital, 2019.

LA PORTA, L. Crise orgânica. In: LIGUORI, Guido; VOZA, Pasquale (orgs.).

Dicionário Gramsciano. São Paulo: Boitempo, 2017.

LULA DA SILVA, L. I. Carta ao povo brasileiro, 2002. Disponível em:

http://www.iisg.nl/collections/carta_ao_povo_brasileiro.pdf. Acesso em: 11/2019.

SKAF, P. Muito prazer, somos a Fiesp. Apoiamos Bolsonaro, que pôs o país no rumo certo. Folha de São Paulo, Opinião, publicado em: 22 jan. 2020. Disponível em: https://www1.folha.uol.com.br/opiniao/2020/01/muito-prazer-somos-afiesp.shtml?utm source $=$ facebook\&fbclid $=$ IwAR1 mIfwh6dGtyywNNVDL 1gGsWd4kTrajMipIpYBQI0bZzOvsjXIxdSY I. Acesso em: 2 maio 2020.

MARTINS, A. S. Formulações da classe empresarial para a formação humana: da educação política à educação escolar. Revista Contemporânea de Educação, vol. 10, n. 20, julho/dezembro de 2015.

MARTINS, E. M. Movimento "Todos pela Educação": um projeto de nação para a educação brasileira. Dissertação (mestrado) - Universidade Estadual de Campinas (Unicamp), Faculdade de Educação. Campinas/SP, 2013.

NEVES, L. M. W (Org.). Direita para o social e esquerda para o capital: os intelectuais da nova pedagogia da hegemonia. São Paulo: Xamã: 2010.

OLIVEIRA, F. Hegemonia às avessas. In: OLIVEIRA, Francisco; BRAGA, Ruy; RIZEK, Cibele. Hegemonia às avessas: economia, política e cultura na era da servidão financeira. São Paulo: Boitempo, 2010.

POULANTZAS, N. Poder político e classes sociais. 2 ed. São Paulo: Martins Fontes, 1986.

RODRIGUES, M. V. "O ministro é gerencialmente incompetente", diz ex-dirigente do Inep sobre Vélez. [Entrevista a Renata Mariz]. O Globo, Educação, publicado em: 27 mar. 2019. Disponível em: https://oglobo.globo.com/sociedade/educacao/o-ministroegerencialmente-incompetente-diz-ex-dirigente-do-inep-sobre-velez-rodriguez-23553539. Acesso em: 12 out. 2019. 
Recebido em: 20/04/2019

Aceito em: 05/05/2020.

Publicado online em: 10/05/2020 